\title{
Key Performance Indicators for Lean: Literature Review and Recommendations
}

\author{
Marjan Todorov $^{1}$, Prof. Bojan Jovanoski ${ }^{2 *}$, Prof. Robert Minovski ${ }^{3}$ \\ ${ }^{1,2,3}$ Faculty of Mechanical Engineering: Institute of Production Engineering and Management, str. Karpos II bb, \\ Skopje, Macedonia
}

*Corresponding Author: Marjan Todorov, graduated mechanical engineer, Faculty of Mechanical Engineering: Institute of Production Engineering and Management, str. Karpos II bb, Skopje, Macedonia

\begin{abstract}
This article solely purpose is to extract the most commonly used key performance indicators from the literature which deal with theoretical or practical case studies of lean implementation in organizations. The methodological approach towards selection initiated with research of the world paper databases. It continued with unification of the indicators with the same meaning. Furthermore, these indicators would be put through specific statistic filter methods in order to define the most commonly used ones. These are: Work in progress (14), Inventory (12) Lead time (12), Cycle time (12) and Value added time (7). The values in brackets are taken from the analyzed literature and they represent the total frequency of appearance of each KPI respectively.
\end{abstract}

Keywords: key performance indicators, literature review; lean, performance, lean evaluation,

\section{INTRODUCTION}

Lean in its essence, it's all about separating the value in the system, while reducing or eliminating the wastes that don't add value to the process or product. As any other application, comes hand in hand with a set of tools which are intended to help successful implementation (Womack et al. 1992). Nowadays, lean is widely accepted even as an organizational methodology and way of thinking and working with proven track of influencing the organizational culture. In (Jalal 2017), we can find about the influences of organizational multi-culture on the leadership's decision making, which is an essential of the organizational culture, i.e. how the business is going through the process of making decisions.

This topic and the definition of lean indicators is still not widely investigated and defined, as we can find many authors and lean implementation case studies that use different sets of indicators in their studies. There is substantive disagreement about what comprises lean production and how it can be measured (Ward, Peter T; Shan 2007). This offers space for investigation and research on the matter.

The common practice during lean implementation starts with mapping out the current state of the system by using the lean tool value stream mapping. Without any further due and getting into details, the logical outcome of this initial mapping is an overview of the current state of the process. In (Womack 2014), the foundations of value stream mapping idea and process steps are given. Value stream mapping (VSM) in its core offers qualitative and quantities overview of the logistic, material and information flows.

While criteria in general, are used for evaluation of a specific process, such as choosing the best supplier(Carnero \& López 2016), the focus area of this paper lays on the quantification of the internal process improvements, i.e. which key performance indicators are used or/and should be used for monitoring and measuring the lean implementation. The conveyed research in this paper should give answers to the following key questions:

1. Which key performance indicators are followed during lean implementation?

2. Which key performance indicators should be followed (put more attention to them)?

3. To which degree, the use of lean tools in the organizations helped in their process improvementsmeasured and quantified by the selected key performance indicators? 


\section{RESEARCH METHODOLOGY - OVERVIEW AND FINDINGS}

The flow of the conveyed research is led by the methodology given in Figure 1.

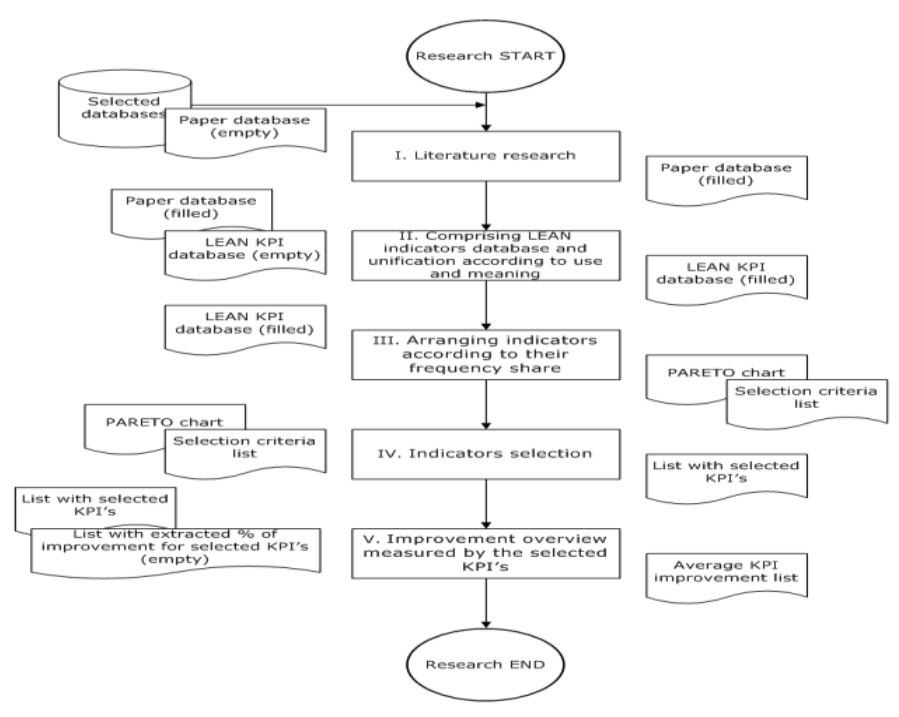

Figure1. KPI selection methodology

Key phases of the methodology are consisted from:

1. Literature research - outcome from this phase is the paper database

2. Comprising lean indicators database and unification according to use and meaning - outcome from this phase is the full list of used KPI's

3. Arranging indicators according to their frequency share - outcome from this phase is the Pareto chart of the list of used KPI's

4. Indicators selection - by using the methodology criteria explained in details in 2.4 the selection of the recommended set of indicators is done

5. Improvement overview measured by the selected KPI's - outcome from this phase is the Average KPI improvement list, that can serve as a benchmark because it contains the average values for process improvement as measured by the selected indicators in the previous phase

In the following paragraph, a sum up overview will be shown of the main research characteristics which comprise its foundations and their intent is to reflect the main research directions:

- Analyzed literature time frame covers papers from: Nov 2001 - Dec 2015

- Sources: online paper databases generators

- emeraldinsight.com

- inderscience.com

- elesevier.com

- ieeexplore.ieee.org

- taylorandfrancis.com

- scientific.net

- leanthinking.org

- scholar.google.com

- Key words used in the research:

- lean parameters

- lean manufacturing parameters

- lean indicators

\subsection{Phase 1: Literature Research}

During this empirical research, a total of 54 papers from different authors were processed. With simple filtering and removal of the repeating subjects, a total of 31 unique papers are gathered. The 
conveyed research set aside two different types of papers, theoretical papers and practical case study papers. The theoretical papers are processing out theoretical elements, while the latter are processing practical case study implementation of lean. APPENDIX 1 summarizes the processed world literature from the 3 online international databases, while using the specific key words given above.

\subsection{Phase 2: Comprising Lean Indicators Database and Unification According to use and Meaning}

The total number of indicators that are extracted from the analyzed literature is 78 . This initial set of gathered indicators was reassembled using criteria for meaning and application in the researched papers. The result was a final list of 51 unique indicators. This is a pure reflection of the wide range and vast application that lean has. An example for indicator unification by using the criteria for meaning and application is represented in Table 2.

Table2. An example for unification of lean terms / indicators

\begin{tabular}{|c|c|c|c|c|}
\hline & VARIANT 1 & VARIANT 2 & VARIANT 3 & VARIANT 4 \\
\hline Inventory & Finished goods & Total stock & & \\
\hline Cycle time & Total cycle time & & & \\
\hline WIP & Work in progress & Intermediate parts & Semifinal product & \\
\hline Change Over & Set up time & Die change & & \\
\hline Manpower & Operators & Workforce & Labor & \\
\hline
\end{tabular}

In this phase of the research, we give an answer to the previously set question: "Which key performance indicators are followed during lean implementation?"

Figure 2 joins the paper database and the extracted unique key performance indicators into one. The intent is to map the used KPI with the paper that it was originally extracted from.

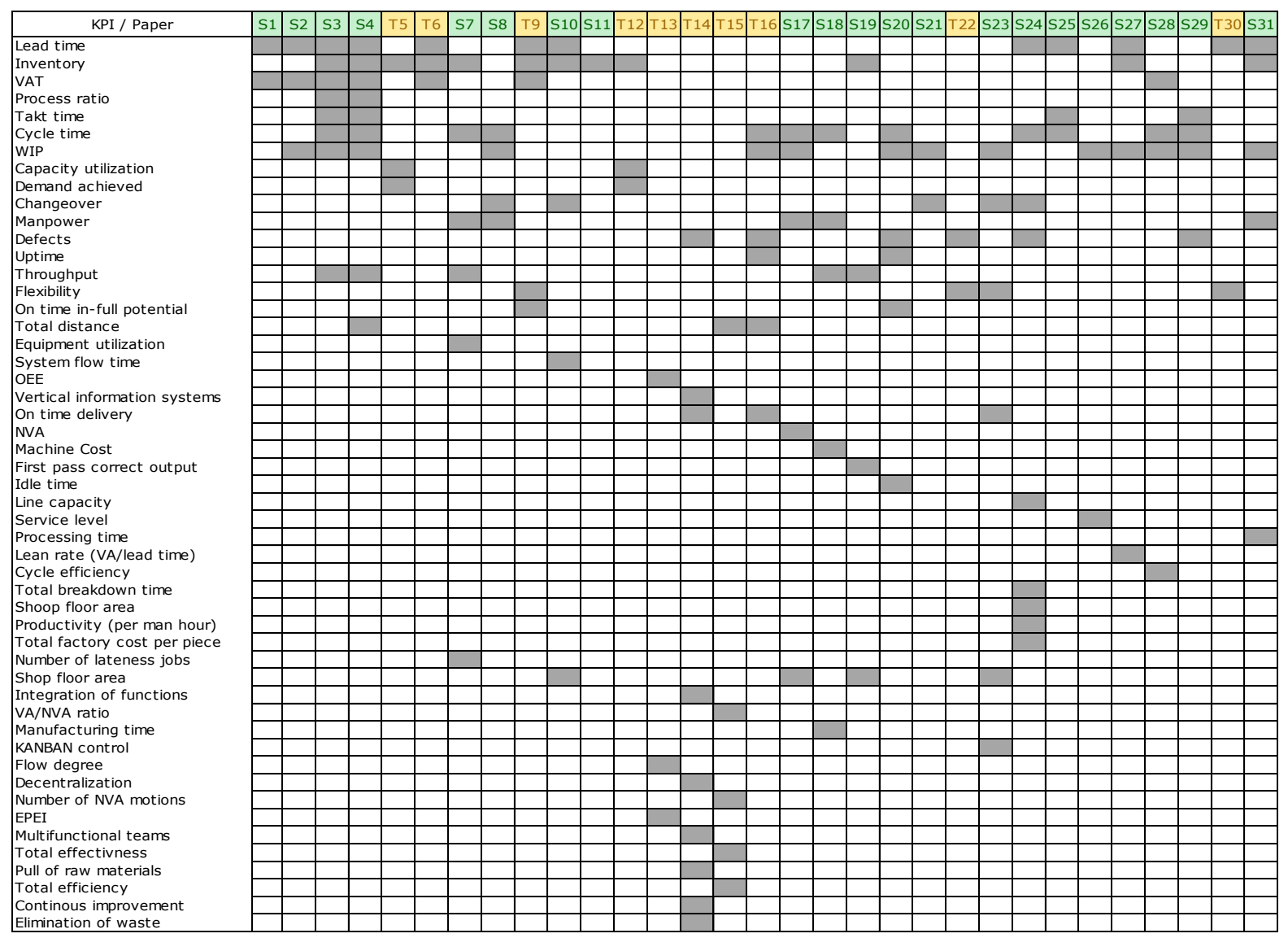

Figure2. Overview of used KPI in the condemned research

Legend details are shown below:

- Papers which are processing real practical case study of lean implementation are marked with "S" and colored with green;

- Papers which are processing theoretical cases of lean implementation are marked with " $\mathrm{T}$ " and colored with yellow; 
- Lean KPI's that are used by the authors are presented on the left side;

- Paper versus KPI matching is represented with grey color;

The result was a final list of 51 unique indicators. This is a pure reflection of the wide range and vast application that lean has.

An example for indicator unification by using the criteria for meaning and application is represented in Table 3.

Table3. An example for unification of lean terms / indicators

\begin{tabular}{|c|c|c|c|c|}
\hline & VARIANT 1 & VARIANT 2 & VARIANT 3 & VARIANT 4 \\
\hline Inventory & Finished goods & Total stock & & \\
\hline Cycle time & Total cycle time & & & \\
\hline WIP & Work in progress & Intermediate parts & Semifinal product & \\
\hline Change over & Set up time & Die change & & \\
\hline Manpower & Operators & Workforce & Labor & \\
\hline
\end{tabular}

In this phase of the research, we give an answer to the previously set question: "Which key performance indicators are followed during lean implementation?"

Figure 3.joins the paper database and the extracted unique key performance indicators into one. The intent is to map the used KPI with the paper that it was originally extracted from.

\subsection{Phase 3: Arranging Indicators According to their Frequency Share}

The Pareto chart was selected as the most suitable tool for analysis of the frequency of appearance of a certain indicator in the reviewed papers. The reasons behind this decision are comprised from the possibility for clear and simple overview of the frequency of a given indicator from the total, as well as the fact that this tool consists from elements of cumulative calculations by which it's very easy to determine the "share" or how dominant a certain indicator was along the analyzed papers, expressed in a quantities manner. It gives a powerful overview of the distribution and it contains the 80/20 rule, which could be used for prioritizing.

The Pareto chart is presented in Figure 3.

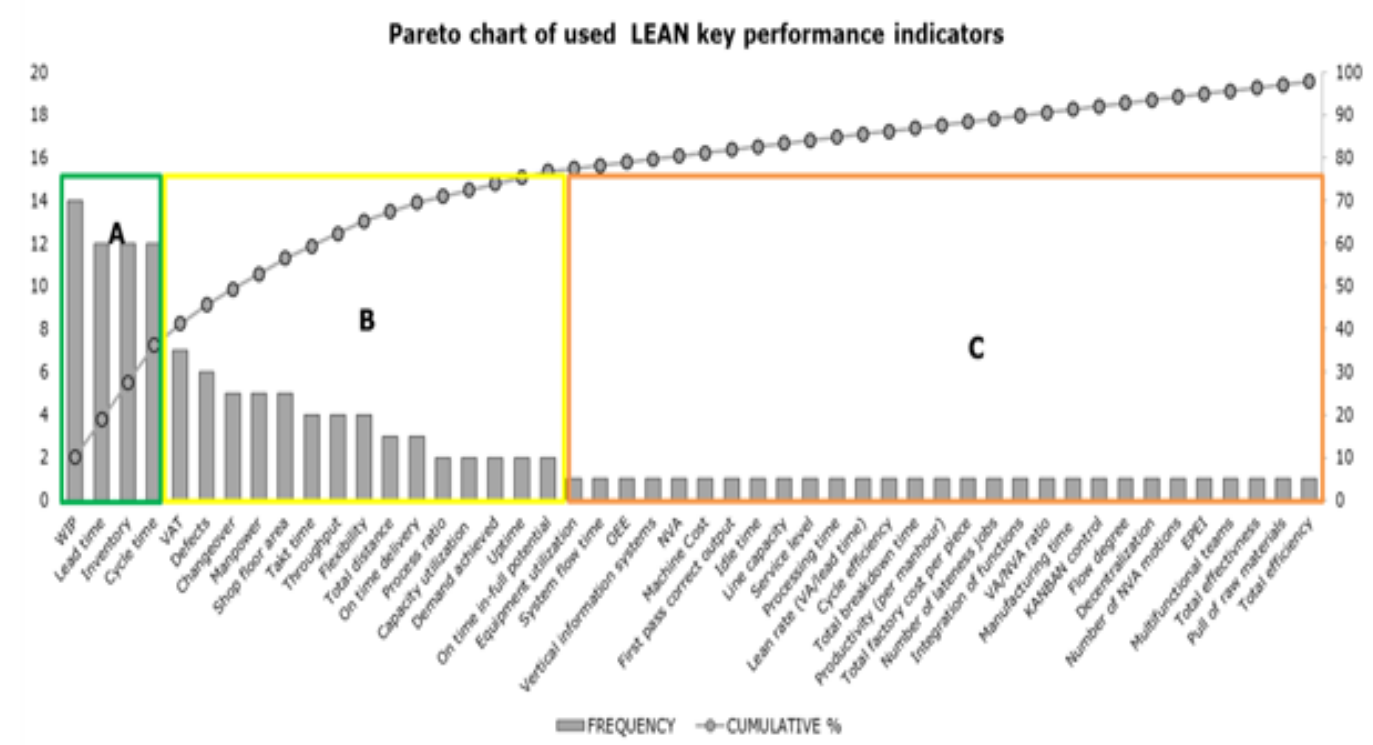

Figure3. Pareto frequency of used KPI in condemned research

\subsection{Phase 4: Indicators Selection}

For the purpose of establishing a statistically supported approach, a statistical tool was used, along with some of its filtering and highlighting features that its sole purpose is to help in the decision making process. These filtering criteria methods are described fully below

- Separation of the indicators according to their frequency share and highlighting the "top $10 \%$ " (presented with green color);

- Separation of the indicators according to their frequency share by using a specific conditional highlighting (presented with the shape of colored circles with black); 
- Separation of the indicators according to their share by using a specific conditional highlighting (presented with the length of the color coding, from maximum to minimum extension of the yellow bar)

According to the given criteria for selection of the KPI's, this logic will be used for final indicator selection:

a) The authors will take into selection the top $10 \%$ indicators marked with green color;

b) The authors will take into selection the dominant full colored circles and the one that is half colored, only because this indicator separates from the others (all others are either $1 / 4$ colored or non-colored);

c) The authors will take into selection the bar length that cross matches with the previously two applied filter methods;

The results are presented in Table 4.

According to the given criteria and the logic for interpretation of the results, the following key performance indicators are selected:
a. WIP
b. LEAD TIME
c. INVENTORY
d. CYCLE TIME
e. VAT

This phase of the methodology answers the previously set question: "Which key performance indicators should be followed?"

Table4. KPI selection

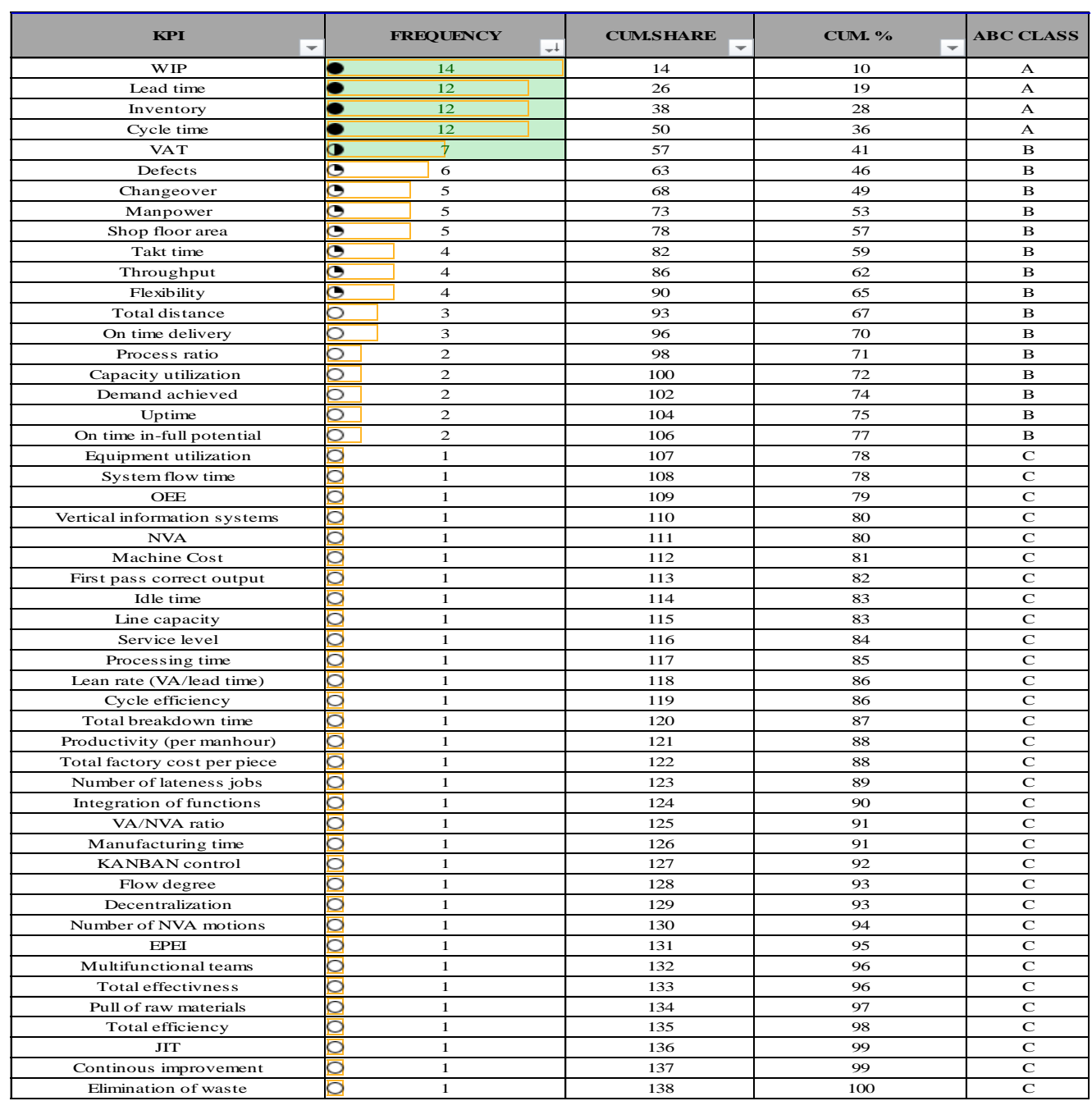




\subsection{Phase 5: Improvement Overview Measured by the Selected KPI's}

This phase extracts the benefit, i.e. the quantification of the lean implementation, as measured by the selected key performance indicators. Table 5.represents the average improvement of the used KPI's in the processed literature.

It answers the last question stated in the beginning of this paper: "By which degree, the use of lean tools in the organizations helped in their process improvements - measured and quantified by the selected key performance indicators?"

The interpretation of the results in the table below is as follows (a specific feature conditional formatting - color scaling is applied in order to rank the data and color it accordingly - from most green that represents the KPI with the greatest impact to most pale green that represents the KPI with the lowest measured improvement):

- The lean implementation in the reviewed literature had greatest impact on the KPI "VAT" (Value added time);

- With an average improvement in the 30-40\% range are "WIP" (Work in Progress) and "Lead time";

- The lean tools used in the reviewed papers had an average improvement factor $<30 \%$ on "Inventory" and " Cycle time;

Table5. Representation of average improvement of the used KPI in the reviewed literature

\begin{tabular}{|c|c|c|c|c|c|}
\hline PAPER / KPI & VAT & WIP & Lead time & Inventory & $\begin{array}{l}\text { Cycle } \\
\text { time }\end{array}$ \\
\hline $\mathrm{S} 1$ & 0,46 & & 0,3 & & \\
\hline $\mathrm{S} 2$ & 2 & 0,9 & 0,7 & & \\
\hline S3 & 0,02 & 0,45 & 0,6 & 0,6 & 0,2 \\
\hline S4 & 0,33 & 0,74 & 0,67 & 0,8 & 0 \\
\hline T5 & & & & NV & \\
\hline T6 & $\mathrm{NV}$ & & NV & NV & \\
\hline S7 & & & & 0,25 & 0,41 \\
\hline S8 & & 0,82 & & & 0,3 \\
\hline T9 & NV & & NV & NV & \\
\hline $\mathrm{S} 10$ & & & 0,86 & 0,1 & \\
\hline $\mathrm{S} 11$ & & & & NV & \\
\hline T12 & & & & NV & \\
\hline \multicolumn{6}{|l|}{ T13 } \\
\hline \multicolumn{6}{|l|}{ T14 } \\
\hline T15 & & & & & \\
\hline T16 & & 0,01 & 0,06 & & 0,02 \\
\hline T16 & & 0,85 & & & 0,64 \\
\hline $\mathrm{S} 18$ & & & & & 0,41 \\
\hline $\mathrm{S} 19$ & & & NV & NV & \\
\hline S20 & & 0,01 & & & 0,03 \\
\hline $\mathrm{S} 21$ & & NV & & & \\
\hline T22 & & & NV & & \\
\hline $\mathrm{S} 23$ & & NV & & & \\
\hline S24 & & & 0,84 & & 0,16 \\
\hline $\mathrm{S} 25$ & & & 0,11 & & 0,11 \\
\hline S26 & & 0,34 & & & \\
\hline S27 & & 0,1 & 0,1 & 0,5 & \\
\hline $\mathrm{S} 28$ & 0,89 & 0,3 & & & 0,3 \\
\hline $\mathrm{S} 29$ & & NV & & & NV \\
\hline T30 & & & NV & & \\
\hline S31 & & 0,97 & 0,92 & 0,97 & \\
\hline $\begin{array}{l}\text { AVERAGE } \\
\text { IMPROVEMENT }\end{array}$ & 0,53 & 0,39 & 0,34 & 0,27 & 0,22 \\
\hline
\end{tabular}

LEGEND details are shown below:

\begin{tabular}{|c|c|}
\hline & The indicator was not included in that paper \\
\hline NV & There is no given value for made improvement for the certain indicator in that paper \\
\hline
\end{tabular}

The KPI's shown above represent the core of the conducted study. Their application ranges all across different scope of industries. Furthermore, they are used for quantification of a variety of different 
segments. In (Gandolf R. Finke, Mahender Singh, 2012) through lead time the various disruptions to operations that can lead to deviations are studied. Lead time is a key performance indicator also studied in (Serrano, 2016) where the study explains how the takt time approach can imply an increase of the manufacturing efficiency, where a key outcome is an increase in the reliability of lead time.

In a study of LEAN line balancing (Koichi Nakade, Akiyasu Ito, 2015),cycle time is used as a quantification parameter between different line balancing strategies working with optimal number of workers. In another study, (Mei Yong Chong, Joshua Prakash, Suat Ling Ng, RazlinaRamli, 2013), WIP is used as an evaluation strategy for two different sets of KANBAN systems.

\section{CONCLUSION}

The key performance indicators used in lean implementation were a main focus point of this paper. The results have shown that authors have used many different indicators for measuring their success of lean implementation. This research paper took a deep-dive into the indicators that have been used up in the literature in order to make a distinctive summary.

Further on, this initial set of extracted parameters from the literature, was being decomposed by applying statistical methods in order to distinguish the most commonly used indicators. This extracted set is being recommended to be used in further lean case studies.

The conclusion of this paper will be finalized by answering the questions that were set as an imperative for writing this paper:

\subsection{Which Key Performance Indicators are followed During Lean Implementation?}

The answer to this question can be found and extracted from Figure 2.2, where we defined a total of 51 unique indicators that the authors were following in their respective papers. Overall as a brief summary, the researchers were following time indicators as takt time, uptime, system flow time, idle time, processing time, lean rate, manufacturing time, non-value added time.

Furthermore, they followed a group of indicators that determines the efficiency and the system capacity were extracted, such as: capacity utilization, demand achieved, throughput, equipment utilization, and many others.

\subsection{Which Key Performance Indicators should be followed?}

By using the Pareto approach and arranging the used indicators according to their frequency share, along with using some advanced statistical filtering, a total of 5 key performance indicators were selected, which are presented in Table 5.

Namely, these are: VAT, WIP, Lead time, Inventory and Cycle time. These indicators are the foundation of the conveyed research and they are directly answering the complementary purposes which are set in the abstract, at the very beginning of this paper. These indicators could be used as a helping foundation in the course of future research papers which are processing the subject of lean implementation in the organizations. The very single purpose is efficient lean monitoring process, as well as setting up an efficient monitoring system that will properly reflect the quantification of the used lean methods.

\subsection{By Which Degree, the use of Lean Tools in the Organizations Helped in their Process Improvements, Measured and Quantified by the Selected Key Performance Indicators?}

The impact the used lean tools had, and all that monitored through the lens of the selected KPI's, it's shown in Table 5. The average KPI improvement showed an average values ranging from 53\% for VAT to $23 \%$ for Cycle time. These results can serve as a benchmark while making comparisons how successful is the lean implementation in any future research papers, related with this subject.

\subsection{Discussion Points}

During the research, a wide range of used indicators is noticed, which is only confirmation for the wide application of lean. While studying the used indicators in the researched papers, a major difference is noticed along the theoretical papers and the practical case study papers.

Namely, the practical case study papers are monitoring and measuring only quantitative indicators which can be easily measured. On the other hand, the theoretical papers, besides the quantitative 
indicators, are using also qualitative indicators such as on time in - full potential, vertical information systems, integration of functions, decentralization and others.

This paper extracted the most common used indicators from the analyzed literature. Dealing with such a delicate nature, especially in the field of lean implementation, indicators should be taken with caution. Authors are aware of the fact that indicators in this field can vary from company to company, even from department to department. Many factors impact which indicators will be followed in an organization, whether those are customer or internally driven. This paper only outlines the statistically most commonly used.

The limitations of the carried study in this paper were impacted by available recourses on-hand. The practical limitations of this study are that these extracted key performance indicators are not separated by industry nor application and that is the main reason why ones must be taken with caution. The theoretical limitations are impacted by the width of the research, in the number of international databases included for analysis.

Both practical and theoretical limitations, together with the findings in this paper represents a baseline on which future studies can develop or start with, whether a practical case study is being developed in a real company or a theoretical lean implementation study is being done.

\section{REFERENCES}

[1] Abdulmalek, F.A. \& Rajgopal, J., 2007. Analyzing the benefits of lean manufacturing and value stream mapping via simulation: A process sector case study. International Journal of Production Economics, 107(1), pp.223-236.

[2] Ar, R., 2012. Production Flow Analysis through Value Stream Mapping: A Lean Manufacturing Process Case Study. , 41(Iris), pp.1727-1734.

[3] Carnero, M.C. \& López, A.B., 2016. Multicriteria Model for the Choice of Best Battery Provider. , pp.2131.

[4] Chowdary, B. V \& George, D., 2011. Improvement of manufacturing operations at a pharmaceutical company A lean manufacturing approach. Journal of Manufacturing Technology Management, 23(1), pp.56-75.

[5] Cuatrecasas-Arbós, Lluís, Jordi Fortuny-Santos, Patxi Ruiz-de-Arbulo-López, C.V.-S., 2015. Monitoring processes through inventory and manufacturing lead time. Industrial Management \& Data Systems, 115(5), pp.951-970.

[6] Detty, R.B. \& Yingling, J.O.N.C., 2000. Quantifying benefits of conversion to lean manufacturing with discrete event simulation: A case study. International Journal of Production Research, 38(2), pp.429445.Availableat:http://www.scopus.com/inward/record.url?eid=2s2.00034688387\&partnerID=40\&md5=8 a6eff086761a6181e353cf3972f23a6.

[7] Ghosh, M., 2012. Lean manufacturing performance in Indian manufacturing plants. Journal of Manufacturing Technology Management, 24(1), pp.113-122.

[8] Gulshan Chauhan, T.P.S., 2013. Measuring parameters of lean manufacturing realization. Measuring Business Excellence, 16(3), pp.57-71.

[9] Gurumurthy, A. \& Kodali, R., 2009. Application of value stream mapping and simulation for the design of lean manufacturing systems: a case study. Int. J. Simulation and Process Modelling, 5(3), pp.192-204.

[10] Gurumurthy, A. \& Kodali, R., 2011. Design of lean manufacturing systems using value stream mapping with simulation: A case study. Journal of Manufacturing Technology Management, 22(4), pp.444-473.

[11] Hayati, N. et al., 2013. Case Study: The Methodology of Lean Manufacturing Implementation. , 393, pp.3-8.

[12] Jalal, A., 2017. Impacts of Organizational Culture on Leadership's Decision- Making. , pp.1-8.

[13] Karim, A. \& Arif-uz-zaman, K., 2013. A methodology for effective implementation of lean strategies and its performance evaluation in manufacturing organizations. , 19(1), pp.169-196.

[14] Khanchanapong, T. et al., 2014. The unique and complementary effects of manufacturing technologies and lean practices on manufacturing operational performance. International Journal of Production Economics, 153, pp.191-203. Available at: http://dx.doi.org/10.1016/j.ijpe.2014.02.021.

[15] Mahfouz, A. \& Arisha, A., 2013. Lean distribution assessment using an integrated framework of value stream mapping and simulation. Journal of Chemical Information and Modeling, pp.1-10.

[16] Martõ, A. \& Sa, Â., 2001. Lean indicators and manufacturing strategies. , 21(11), pp.1433-1451. 
[17] Marvel, J.H. \& Schaub, M.A., 2005. Proceedings of the 2005 Winter Simulation Conference M. E. Kuhl, N. M. Steiger, F. B. Armstrong, and J. A. Joines, eds. , pp.2112-2118.

[18] Mohd, J. \& Mojib, S., 2015. Production line analysis via value stream mapping: a lean manufacturing process of color industry. Procedia Manufacturing, 2(February), pp.6-10. Available at: http://dx.doi.org/10.1016/j.promfg.2015.07.002.

[19] Nallusamy, S., 2016. Lean Manufacturing Implementation in a Gear Shaft Manufacturing Company Using Value Stream Mapping. , 21, Pp.231-237.

[20] Robinson, S. Et Al., 2012. Simlean: Utilising Simulation in the implementation of lean in healthcare. European Journal of Operational Research, 219(1), pp.188-197.

[21] Roessler, M.P., Metternich, J. \& Abele, E., 2014. Learning to See Clear: Quantification and Multidimensional Assessment of Value Stream Mapping Alternatives Considering Variability Business and Management Research, 3(2). Available at: http://www.sciedu.ca/journal/index.php/bmr/article/ view/4778.

[22] Rosario Domingo, Roberto Alvarez, Marta Melodía Peña, R.C., 2007. Materials flow improvement in a lean assembly line : a case study. Assembly Automation, 27(2), pp.141-147.

[23] S. Vinodh, M. Somanaathan, K.R.A., 2013. Development of value stream map for achieving leanness in a manufacturing organization. Journal of Engineering, Design and Technology, 11(2), pp.129-141.

[24] Shivdasini Singh Amin, Rakesh Atre, Ankur Vardia, B.S., 2014. Lean machine manufacturing at Munjal Showa limited. International Journal of Productivity and Performance Management, 63(5), pp.644-664.

[25] Sihn, W. \& Pfeffer, M., 2013. A method for a comprehensive value stream evaluation. CIRP Annals Manufacturing Technology, 62(1), pp.427-430. Available at: http://dx.doi.org/10.1016/j.cirp.2013.03.042.

[26] Singh, B. \& Sharma, S.K., 2009. Value stream mapping as a versatile tool for lean implementation : an Indian case study of a manufacturing firm. , 13(3), pp.58-68.

[27] Sleem, S.N., Helal, M. \& Elassal, A.M., 2014. Using Computer Simulation in Lean Manufacturing Implementation. 16th Intl. Conf. on Applied Mechanics \& Mechanical Engineering. Available at: https://www.researchgate.net/publication/280003866_Using_Computer_simulation_in_Lean_Manufacturi ng_Implementation.

[28] Solding, P. \& Gullander, P., 2009. Concepts for simulation based Value Stream Mapping. Winter Simulation Conference (WSC), pp.2231-2237.

[29] Standridge, C.R. \& Fulton, W., 2006. Why Lean Needs Simulation. Proceedings of the 2006 Winter Simulation Conference, pp.1907-1913.

[30] Taj, S., 2008. Lean manufacturing performance in China : assessment of 65 manufacturing plants. Journal of Manufacturing Technology Management, 19(2), pp.217-234.

[31] Ward, Peter T; Shan, R., 2007. Defining and developing measures of lean production. Journal of Operations Management, 25(4), pp.785-805.

[32] Womack, J.P., 2014. Lean Thinking Banish waste and create wealth in your corporation, Available at: http://www.diva-portal.org/smash/record.jsf?pid=diva2:748037\&dswid=1590.

[33] Womack, J.P., Jones, D.T. \& Roos, D., 1992. The machine that changed the world. Business Horizons, 35(3), pp.81-82.

[34] Yang, T. et al., 2015. Lean production system design for fishing net manufacturing using lean principles and simulation optimization. Journal of Manufacturing Systems, 34, pp.66-73. Available at: http://dx.doi.org/10.1016/j.jmsy.2014.11.010.

\section{AUTHORS' BIOGRAPHY}

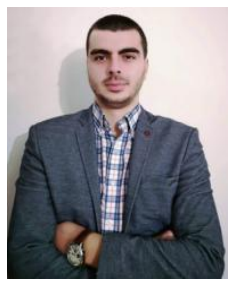

Marjan Todorov, is a graduated mechanical engineer, currently finishing his master thesis at the Faculty of Mechanical Engineering, Division of Industrial Engineering and Management. His academic preferences are the joint use of both Lean and Discrete Event Simulations as part of the improvement approach. He has gained strong automotive experience with a proven track of continuous improvement and problem solving projects. He is a certified Lean Six Sigma Green Belt.

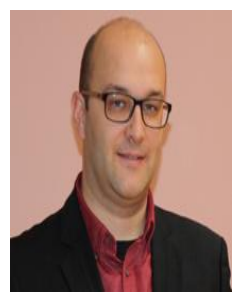

Bojan Jovanoski, is an assistant Professor at the Faculty of Mechanical Engineering - Skopje, Division of Industrial Engineering and Management. He has been involved with simulation and modeling since 2006. His goal is to apply simulation techniques in research and productivity improvement projects. The combination of Lean and simulation is the current research he is working on. 


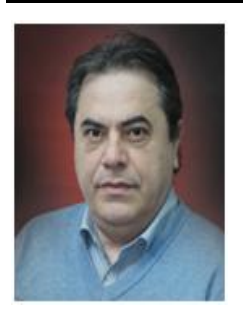

Robert Minovski, holds a doctorate in Technical Sciences from the University of Ss Cyril and Methodius in Skopje, R. Macedonia. He is a Professor at the Faculty of Mechanical Engineering, University of Ss Cyril and Methodius in Skopje. He is a fellow of the European Academy on Industrial Management (AIM). His research interests are in the fields of Enterprise Restructuring, Performance Measurement Systems, Business Modelling and Simulation.

Citation: Marjan Todorov, et.al (2019)" Key Performance Indicators for Lean: Literature Review and Recommendations", International Journal of Modern Studies in Mechanical Engineering, 5(1), pp. 27-36. DOI: http://dx.doi. org/10.20431/2454-9711.0501002

Copyright: () 2019 Authors, This is an open-access article distributed under the terms of the Creative Commons Attribution License, which permits unrestricted use, distribution, and reproduction in any medium, provided the original author and source are credited. 